\title{
Результативность трудового поведения домохозяйств в условиях трансформации отношений собственности и условий занятости ${ }^{1}$
}

\author{
А.Л. ТЕМНИЦКИЙ*
}

\begin{abstract}
*Александр Лазаревич Темницкий - кандидат социологических наук, доцент, кафедра социологии, Московский государственный университет (институт) международных отношений МИД РФ (МГИМО); старший научный сотрудник, Институт социологии Федерального научно-исследовательского социологического центра РАН. Адрес: 119454, Москва, проспект Вернадского, д. 76. E-mail: taleksandr@list.ru

Цитирование: Темницкий А.Л. (2020) Результативность трудового поведения домохозяйств в условиях трансформации отношений собственности и условий занятости // Мир России. Т. 29. № 2. С. 134-155. DOI: 10.17323/1811-038X-2020-29-2-134-155
\end{abstract}

В настоящей статье проблема результативности в трудовом поведении наемных работников анализируется с позиций иелей и интересов домохозяйства. В этой связи в качестве важнейших результирующих показателей трудового поведения рассматриваются размер оплаты труда, соотнесенный с затратами времени, удовлетворенность оплатой и работой в изелом, уверенность в занятости. В качестве информаџионной базы исследования используются данные Российского мониторинга экономического положения и здоровья населения (RLMS-HSE) за 1994-2017 г2. В статье дается диагностика эффективности трудового поведения городских наемных работников, занятых на формальном рынке труда, с учетом изменений в отношениях собственности и стабильности занятости в организациях. С помощью регрессионного анализа с фиктивными переменными выявлен вклад занятости на частных предприятиях в объяснение размера зарплаты. Показаны признаки потери привлекательности занятости на частных предприятиях, сохранения стабильности условий занятости для абсолютного большинства работников (за исключением ситуации с рабочим временем), вынужденного характера трудовой и профессиональной мобильности, роста уверенности в занятости при различных проявлениях динамичности в поведении, невозможности уделять больше времени семье из-за неготовности поступиться возможностями для заработка.

1 Статья подготовлена по результатам исследований, выполненных за счет бюджетных средств по государственному заданию Финуниверситету по теме «Семейные домохозяйства как экономический субъект». 
Ключевые слова: трудовое поведение, домохозяйство, стратегия максимизации труда, баланс работы и семьи, отношения собственности, стабильная занятость, рынок труда, наемные работники

Обращение к трудовому поведению как объекту исследования может отталкиваться либо от целей организации, либо от целей домохозяйства. В первом случае оно сводится преимущественно к рассмотрению трудового поведения как «в основном рационально реализуемому комплексу действий и поступков работника, связанных с синхронизацией его профессиональных возможностей и интересов с функциональным алгоритмом производственного процесса» [Верховин 2003, с. 13]. Среди западных авторов весьма широко распространены подход к анализу трудового поведения на уровне рабочего места и определение его эффективности в зависимости от характеристик личности работника, лидерских качеств, культуры, образования и системы контроля над его поведением в организации. Центральным фактором здесь становится увязывание поведения персонала с достижением организационных целей: поведение считается эффективным в том случае, если сотрудники действуют в соответствии с предписываемыми организацией установками [Bowen, Ostroff 2004]. Его основные проявления - ответственность в работе, качество труда, интенсивность труда, степень трудовой отдачи, выполнение заданий, дисциплина, инициативность, использование рабочего времени, соблюдение и отклонения от регламентируемых правил, потенциальная текучесть, удовлетворенность работой, идентификация с предприятием и т.п. - являются традиционными предметами исследований социологии и экономики труда [Ядов 2006, с. 353].

В центре нашего внимания находятся работник как представитель домохозяйства, его стратегии занятости и их реализация в конкретных условиях организации ${ }^{2}$ в целях достижения достаточного для нормальной жизни уровня материального благополучия. Традиционно домохозяйство рассматривается как совокупность лиц (чаще всего объединенных семейными и кровными узами), проживающих вместе, имеющих общий бюджет и ведущих совместное хозяйство [Радаев 2005, с. 331]. Социологические исследования XX-XXI вв. указывают на растущую атомизацию индивидов, на то, что фактически все основные решения современные люди, даже являясь членами семьи, стали принимать в основном самостоятельно [Бауман 2005; Бек 2000]. В результате при анализе поведения людей акцент делается преимущественно на их личном выборе, в то время как влияние на него других членов семьи считается второстепенным и учитывается лишь косвенно. В рамках неоклассической теории домохозяйство и индивид априори рассматриваются как тождественные понятия, а домохозяйство трактуется как хозяйствующий субъект, действующий исключительно рационально с учетом возможностей и ограничений, задаваемых рынком труда [Нуреев 2001, с. 47]. Приведенные аргументы позволяют редуцировать современное домохозяйство до уровня индивида, сохраняющего самостоятельность в принятии решений независимо от его семейного статуса. Однако принципиально важным становится учет семейных обязанностей детей до 18 лет; также априорно предположение, что в функцию полезности этого индивида интегрированы повышение благосостояния его близких и интересы членов домохозяйства в целом.

2 Использование терминов «организация», «предприятие» в данной статье отождествляется. 
Исходя из приоритетности целей домохозяйства по отношению к экономической активности индивида на рынке труда, предполагается, что из множества известных методологических подходов к исследованию трудового поведения [Бочаров 2019; Темниикий 2007] адекватными (с учетом обозначенного видения домохозяйства) являются модель экономического человека и связанная с ней стратегия максимизации труда.

Наложение модели экономического человека на реалии трудового поведения современных российских работников предусматривает исключение из анализа (как несущественных вопросов) справедливости в оплате труда, солидарности в отстаивании коллективных интересов, влияния традиций трудовой культуры и целого ряда подобных образований и включение в исследование ситуаций с выбором мест занятости, ориентаций на работу в стабильных условиях занятости в организации или на самозанятость, работу на одну полную ставку на основной работе или на дополнительную работу и приработки, работу по своей профессии или смену профессий и мест занятости. В целом комбинацию ориентаций (выбор и устройство на успешное предприятие, стремление к максимально возможному заработку, желание интенсивно и продолжительно работать) можно рассматривать как проявление стратегии максимизации труда, которая, по данным исследований конца 1990-х гг., являлась ведущей в составе экономического поведенческого комплекса наиболее активных молодых работников развивающейся рыночной экономики [Полякова 1998, с. 145].

Итак, с учетом приоритетной роли домохозяйства трудовое поведение будет считаться эффективным, если его результаты способствуют повышению личного и семейного благосостояния. При таком подходе анализ трудового поведения не замыкается в пределах организации, в него включаются все виды оплачиваемой работы, осуществляемые работником на условиях найма как к юридическим, так и частным лицам, как фиксируемого, так и устного, а также труд на условиях самозанятости и мелкого предпринимательства, исключающего наем других лиц. В данной статье исследование трудового поведения ограничивается рамками занятости в организации. С учетом заявленной ориентации на цели и интересы домохозяйства ведущим становится анализ не содержания, а результирующих показателей трудового поведения, к которым можно отнести размер получаемой зарплаты, фактические затраты времени на работу и уточненный размер заработка с учетом временных затрат, а также такие субъективные показатели, как удовлетворенность зарплатой и работой в целом, оценки уверенности в занятости на внешнем по отношению к организации рынке труда.

Дополнительной рабочей теорией, актуальной для понимания роли домохозяйства в трудовом поведении, которая во многом противостоит модели экономического человека, является теория баланса жизни и труда (work-lifebalance). Обращение к обзорным публикациям по этой теме показало, что чаще всего в них затрагивается проблема баланса между работой и семьей (домом) [Рождественская 2011]. Многочисленные исследования свидетельствуют об обостряющемся конфликте семейных и профессиональных ролей, о чрезмерном доминировании работы над семьей. Утверждается, что в современных условиях семья детерминируется работой настолько, что «корпорации превращаются в своего рода монастыри, абсорбирующие личность во всех ее жизненных проявлениях» [Лимаренко, Прилепко 2014, с. 101]. К основным факторам, негативно влияющим на сочетание 
семьи и работы, чаще всего относят временные перегрузки и необходимость задерживаться на работе [Праведников 2018, с. 177]. Современная ситуация складывается таким образом, что «каким бы ни был уровень доходов или условия найма, практически всех рабочих объединяет отсутствие дилеммы “работа или семья". Для них исходной смысловой точкой является «работа для семьи» [Андреева, Лукьянова 2019, с. 128]. Ранее было выявлено, что главной причиной снижения роли семейной жизни в представлениях об успехе является максимальное значение, придаваемое российскими работниками заработку как высшей ценности работы [Темницкий 2019, с. 295]. В этой связи представляется актуальным включение в анализ таких показателей сбалансированности работы и семьи, как стремление иметь больше времени для семейных и домашних дел и готовность сократить личный доход от работы для увеличения времени на семейную жизнь. Важным показателем для выявления сбалансированности работы и семьи становятся оценки перспектив улучшения положения семьи в связи с особенностями занятости и активности в трудовом поведении.

Для раскрытия характера перемен в трудовом поведении работников за годы реформ и выявления его результативности важно обратиться к тем фундаментальным по своему содержанию условиям занятости, которые оказались принципиально новыми для работника с начала либеральных реформ и продолжают влиять на него до сих пор. Речь идет об изменениях в отношениях собственности на средства производства, а также формах и уровнях стабильности занятости в организациях. Трансформации в отношениях собственности, произошедшие в России за последнюю четверть века, характеризуются как социально радикальные, но недостаточно экономически эффективные [Беляева 2017, с. 40]. На сегодняшний день утрачены былые иллюзии о возможности благодаря приватизации приобщить работников к участию в собственности [Патрушев, Темницкий 1994]; правомерными представляются и утверждения о полном отчуждении трудящихся от ставших частными средств производства [Андреев 2007].

Вместе с тем в установках молодых людей на труд в частном секторе некоторые исследователи увидели отражение формирования новой трудовой этики, основанной на готовности больше трудиться, нести ответственность, проявлять предприимчивость, быть инициативным и активным [Мкртчян, Чистяков 2000, с. 43]. Отмечая привлекательность негосударственных предприятий для российской молодежи, исследователи указывают на роль более высокого уровня организации труда и меньшую значимость социальных льгот [Гориков, Пэйлинь Ли, Голенкова 2012, с. 109]. Предполагалось, что качества наемного работника рыночного типа в основном находят свое применение на предприятиях с частной формой собственностью с их ярко выраженной доминантой высокой зарплаты [Темницкий 2014]. В этой связи можно допустить, что занятость на частных предприятиях по-прежнему в большей степени, чем на государственных, аккумулирует работников с высоким ресурсным потенциалом, способствует большей мобильности и уверенности на рынке труда, дает большие возможности повышать материальное благополучие домохозяйств благодаря интенсивному труду, но неблагоприятно сказывается на достижении сбалансированности между работой и семьей.

В последнее время заметно выросло внимание отечественных исследователей к проблеме стабильности в занятости. Явной предпосылкой этому стал интерес ученых к вопросам актуальности и новизны современного феномена занятости 
и стоящей за ним категории работников, обозначенного Г. Стэндингом как прекариат, который включает в себя индивидов, обладающих низким уровнем дохода, не имеющих постоянной занятости, а вследствие этого и социальных гарантий, и надежной профессиональной идентичности [Стэндинг 2014, с. 23].

Однако следует отметить, что в работах отечественных исследователей прослеживается явная путаница в определении критериев представителей прекариата. Так, согласно категоризации Ж.Т. Тощенко, прекариат составляют занятые на временной работе, работающие неполный рабочий день или получающие случайные приработки, безработные, занятые наемным трудом, мигранты, стажеры и студенты, желающие подработать, а также представители креативных профессий, занятые фрилансом [Тощенко 2018, с. 81-84]. Более широкий подход без выделения категорий предполагает, что к прекариату можно отнести всех наемных работников, которые не имеют стабильной узаконенной формальной занятости со всеми вытекающими из нее правами [Голенкова, Голиусова 2015, с. 49]. Еще больше сложностей возникает с определением удельного веса прекариата в общем числе наемных работников: так, по данным РМЭЗ, выделяются группы с наиболее высокой степенью устойчивости занятости - примерно $6 \%$ наемных работников, с умеренной неустойчивостью занятости - свыше 50\% [Бобков, Вередюк, Колосова, Разумова 2014, с. 25]. По другим данным, в зону риска (попадания в прекариат) относят примерно $27 \%$ работающего населения России [Шкаратан, Карачаровский, Гасюкова 2015, с. 109].

Ввиду путаницы в критериях и определении долей распространенности прекариата мы будем исходить из задачи выявления роли стабильности в занятости по отношению к интересам домохозяйств, а не отнесения работников к заведомо неблагополучным категориям с наклеиванием ярлыка «прекарности» занятости. Так, следование стратегии максимизации труда предполагает уход от различных форм стабильности в труде и ориентацию на мобильность, проявляемую в готовности менять места занятости и профессию, работать дольше нормированной продолжительности рабочего времени, искать дополнительную работу и приработки. Исследования, посвященные мобильности на российском рынке труда, отмечают «нормальность» процессов трудовой мобильности в условиях российского рынка труда, ее подверженность тем же факторам, что и в других странах мира [Гимпельсон, $\mathrm{Ka}$ пелюшников, Шарунина 2016, с. 229]. Отечественный рынок труда отмечается значительной интенсивностью внешней (межфирменной) мобильности, причем более высокие уровни внешней мобильности характерны для мужчин, молодежи, работников, не имеющих высшего образования, «синих воротничков», проживающих в мегаполисах, не состоящих в браке [Гимпельсон, Капелюшников 2017, с. 211-219].

Наша гипотеза основывается на предположении, что для работника хороша только та форма мобильности, которая не является вынужденной, способствует улучшению результирующих показателей трудового поведения и при этом не оказывает разрушительного влияния на семейные ценности. Как отмечал У. Бек, «... связанное с рынком труда требование мобильности оказывается тем ядом, который разъедает семью» [Бек 2000, с. 116].

Перечисление вышеуказанных предпосылок позволяет сформулировать ряд исследовательских вопросов: можно ли сегодня назвать более выигрышной для работников и их домохозяйств занятость на частных предприятиях по сравнению с государственными; что оказалось более успешным для работника - проявления 
его трудовой и профессиональной мобильности или его стабильная занятость; стимулирует ли большая продолжительность рабочего времени достижение более высокого уровня материального благополучия домохозяйств; что способствует повышению ориентации работников на семейные ценности?

Ответы на эти вопросы позволят, на наш взгляд, дать диагностику результативности трудового поведения с учетом изменений в отношениях собственности и стабильности занятости в организации. Достижение данной цели требует решения таких процедурных задач, как обоснование эмпирического объекта, информационной базы исследования, методики и методов анализа.

В качестве эмпирического объекта рассматриваются категории городских наемных работников ${ }^{3}$, которые на момент опроса имели оплачиваемую работу в организациях и различались по наличию семейных обязанностей и детей до 18 лет ${ }^{4}$. Информационной базой исследования является объединенный массив данных РМЭЗ-ВШЭ за 1994-2017 гг. ${ }^{5}$, обращение к которому позволяет рассмотреть временную динамику изменений состояния выделенных факторов и связанных с ними результатов трудового поведения. Для этого были отобраны массивы данных с 4-летним периодом начиная с 1994 г. и данные за последний доступный год наблюдения (2017 г.). Ограничения в анализе определялись наличием интересующих нас переменных в объединенном массиве в разные годы опроса: так, вопросы по показателям сбалансированности работы и семьи задавались только в 2009 г.

Основные результирующие показатели трудового поведения фактологического характера включали в себя размер получаемой заработной платы ${ }^{6}$ и продолжительность рабочего времени ${ }^{7}$. Субъективные показатели результатов трудового поведения (удовлетворенность зарплатой ${ }^{8}$, удовлетворенность работой9, уверенность в занятости на рынке труда ${ }^{10}$, используемые в анализе) были приведены

\footnotetext{
3 Выбор городских работников основывался на предположении об их более высокой трудовой активности. Из анализа исключались работники, проживающие в селах, военнослужащие, законодатели, крупные чиновники, руководители высшего и среднего звена, а также квалифицированные работники сельского, лесного хозяйства и рыболовства.

4 Среди отобранных работников во все годы исследований большая часть состояла в брачных отношениях (как зарегистрированных, так и незарегистрированных), доля которых последовательно снижалась: с $82 \%$ в 1994 г. до $72 \%$ в 2017 г. среди мужчин и с 69 до 57\% - среди женщин. Доля домохозяйств, не имеющих детей до 18 лет, согласно данным в объединенном массиве, начиная с 2004 г. возросла незначительно, однако в динамике заметно снижение доли домохозяйств с одним ребенком (после 2002 г. с 46\% в 2004 г. до 37\% в 2017 г. и рост с двумя и более - с 16 до $22 \%$ соответственно).

5 Российский мониторинг экономического положения и здоровья населения НИУ ВШЭ (RLMS-HSE) проводится Национальным исследовательским университетом «Высшая школа экономики» и ООО «Демоскоп» при участии Центра народонаселения Университета Северной Каролины в Чапел Хилле и Института социологии PAH // http://www.hse.ru/rlms

6 Формулировка вопроса - «Сколько денег в течение последних 30 дней Вы получили по основному месту работы после вычета налогов? Если все или часть денег Вы получили в иностранной валюте, переведите, пожалуйста, все в рубли и назовите общую сумму».

7 Формулировка вопроса - «Сколько часов Вы фактически отработали по основному месту работы в течение последних 30 дней?».

8 Формулировка вопроса - «Насколько Вы удовлетворены или не удовлетворены оплатой Вашего труда?».

9 Формулировка вопроса - «Насколько Вы удовлетворены или не удовлетворены Вашей работой в целом?».

10 Формулировка вопроса - «Представьте себе не очень приятную картину: предприятие, организация, где Вы работаете, по каким-то причинам завтра закроется, и все работники будут уволены. Насколько Вы уверены в том, что сможете найти работу не хуже той, на которой работаете сейчас?».
} 
к единой пятибалльной шкале измерения. Это позволило использовать такие методы анализа, как сравнение средних, однофакторный дисперсионный анализ и множественные сравнения. Для выявления эффектов взаимодействия независимых переменных были применены метод двухфакторного дисперсионного анализа, процедура разбиения файла. Кроме этого, использовались коэффициенты Крамера (в кросс-табуляциях) и Спирмана в построении ранговых корреляций. Для определения вклада основных предикторов в объяснение размера получаемой зарплаты применялся метод построения множественной линейной регрессии с фиктивными переменными.

Указанные нами как фундаментальные по своему содержанию условия занятости (изменения в отношениях собственности и стабильности в занятости) рассматриваются как потенциальные факторы по отношению к изменению и различиям в результирующих показателях трудового поведения.

\section{Фактор формы собственности предприятия}

Обращения к работникам организаций как информантам относительно собственности и отношений, связанных с ней, показывают, что их ответы, как правило, оказываются верными по сути. Работники редко ошибаются в ответах на вопрос «Кому принадлежит данное предприятие: отдельному лицу, группе лиц, коллективу или государству?». Об этом свидетельствует незначительная доля затруднившихся ответить на эти вопросы, которая во все годы опросов не превышала 5\%. Кроме того, полученные данные подтверждаются статистикой Росстата, согласно которой доля предприятий с частной формой собственностью составила на 1 января 2017 г. 79\%, что близко к результатам вычислений ${ }^{11}$.

Исходя из ответов на вопросы о том, кто является владельцем, совладельцем предприятия, на котором работают респонденты, были сконструированы три основные типологические переменные, отражающие взаимосвязь государственной и частных форм собственности. Первый тип предприятий, которые были названы «государственными», основан на положительных ответах об участии государства в их собственности и отрицательных - об участии российских частных лиц, коллектива предприятия или российских частных фирм. Второй тип предприятий, названных «частными с участием государства», базировался на основе положительных ответов об участии в собственности как государства, так и частных лиц, коллектива предприятия или российских частных фирм. Третий тип - «частные без участия государства» предприятия - сформирован на основе положительных ответов об участии в собственности частных лиц, коллектива предприятия или российских частных фирм и отрицательных - государства. Тип предприятий, основанный на участии в собственности иностранных фирм и иностранных частных лиц, из-за их незначительного количества (3-5\%) в анализ не включен. И совсем незначительной стала доля работников, считающих, что они являются совладельцами предприятия (1994 г. - 23\%, 2017 г. - 2\%).

11 По данным государственной регистрации на 1 января 2017 г. // http://orenstat.gks.ru/wps/wcm/connect/rosstat_ ts/orenstat/resources/f989c3804a465951a450ec758571d025/n2.pdf 
Рассмотрим динамику занятости работников на предприятиях с различными формами собственности. За анализируемый период произошли радикальные изменения в занятости городских наемных работников: если в 1994 г. три четверти из них были сконцентрированы на государственных предприятиях, то к 2017 г. их доля снизилась более чем вдвое, а на частных предприятиях без участия государства возросла почти в 4 раза и составила 60\% (таблица 1).

Таблица 1. Распределение работников по занятости на предприятиях с различными формами собственности, данные по объединенному массиву РМЭЗ-ВШЭ, 1994-2017 гг., \%

\begin{tabular}{|l|c|c|c|c|c|c|c|}
\hline \multirow{2}{*}{ Типы предприятий } & \multicolumn{7}{|c|}{ Годы опроса } \\
\cline { 2 - 9 } & $\mathbf{1 9 9 4}$ & $\mathbf{1 9 9 8}$ & $\mathbf{2 0 0 2}$ & $\mathbf{2 0 0 6}$ & $\mathbf{2 0 1 0}$ & $\mathbf{2 0 1 4}$ & $\mathbf{2 0 1 7}$ \\
\hline Государственные & 75 & 62 & 52 & 43 & 38 & 37 & 33 \\
\hline Частные с участием государства & 9 & 16 & 13 & 9 & 8 & 7 & 7 \\
\hline Частные без участия государства & 16 & 22 & 35 & 48 & 54 & 56 & 60 \\
\hline Количество ответивших & $\mathbf{2 6 6 2}$ & $\mathbf{2 3 5 6}$ & $\mathbf{3 1 3 4}$ & $\mathbf{3 8 4 6}$ & $\mathbf{5 7 1 3}$ & $\mathbf{4 8 8 6}$ & $\mathbf{4 8 6 8}$ \\
\hline
\end{tabular}

Занятость на предприятиях с разными формами собственности имеет четко выраженную отраслевую специфику, устойчиво сохранявшуюся на всем протяжении проводимых исследований. Большинство работников, занятых на государственных предприятиях, сконцентрированы в отраслях науки, образования, культуры, здравоохранения и социального обслуживания $(58 \%)^{12}$, минимально - в отраслях топливно-энергетического комплекса (ТЭК) (3\%). Модальные группы занятых на частных предприятиях с участием государства представлены в отраслях обрабатывающей промышленности (37\%), строительства, транспорта, связи (28\%), а также в ТЭК (14\%). На частных предприятиях без участия государства - в бытовом обслуживании, торговле и ЖКХ (40\%), строительстве, транспорте, связи (23\%), обрабатывающей промышленности $(22 \%)^{13}$. Другой отличительной особенностью занятых на предприятиях с разными формами собственности является их половозрастной состав. На государственных предприятиях выше доля женщин (64\%), а на частных - мужчин (54\%). С учетом медианного возраста (по объединенной выборке) работников (39 лет) были созданы четыре половозрастные группы. Доля мужчин в возрасте моложе 40 лет оказалась самой высокой на частных предприятиях без участия государства - 32\%, на государственных - 18\%, причем в динамике с 1994 по 2017 г. доля мужчин до 40 лет снизилась на государственных предприятиях с 22 до 14\%. На государственных модальной группой являются женщины старше

\footnotetext{
12 Эти отрасли были объединены в одну группу, также в одну группу были сведены работники отраслей строительства, транспорта и связи, бытового обслуживании, торговли и ЖКХ.

13 Приводятся данные по объединенному массиву. Разбиение по годам связей формы собственности и отраслевой принадлежности предприятия показывает высокую степень устойчивости данных, коэффициент Крамера в диапазоне 0,433-0,486 при $\mathrm{p} \leq 0,01$.
} 
40 лет $-37 \%$, на частных без участия государства $-21 \%$. Кроме того, следует учитывать различия по наличию высшего образования: на государственных доля работников с высшим образованием составила $37 \%$, а на частных - $26 \%$. Выявленные различия являются значимыми для всех годов опроса. Конечно, может показаться, что все указанные особенности обусловлены отраслевой принадлежностью, однако значимые статистические различия (на уровне $\mathrm{p} \leq 0,001$ ) сохраняются и при включении отрасли в качестве третьего контрольного фактора (за исключением случая с наличием высшего образования в ТЭК). Следует также упомянуть, что в последнее время не принято классифицировать предприятия по формам собственности, все чаще их относят либо к бюджетному, либо к коммерческому сектору [Гимпельсон, Шарунина 2015, с. 318]. Однако заметим, что сферы здравоохранения, образования, управления, науки и культуры, занятость в которых рассматривается как одно из оснований для включения в бюджетный сектор, не относятся только к государственным организациям, по крайней мере, $15 \%$ из них - частные.

Важнейшим показателем результативности трудового поведения является получаемый размер зарплаты. Зарплата работников государственных организаций в среднем всегда уступала размеру заработка работников организаций с частной формой собственности (на 3-4 тыс. руб.). Однако существенные (статистически значимые) различия в размерах оплаты труда были обнаружены при сравнении зарплат работников частных и государственных предприятий. Между средними размерами зарплат работников частных предприятий с участием и без участия государства значимых различий нет. Примерно такая же тенденция была выявлена и по другим контролируемым показателям, за исключением фактической продолжительности рабочего времени. С учетом этого, а также незначительной численности работников частных предприятий с участием государства было проведено их объединение в одну группу (частные).

Насколько существенным оказалось влияние различий в занятости на государственных и частных предприятиях на учитываемые показатели результативности в трудовом поведении, можно заключить при анализе данных таблищы 2.

В целом в период 1994-2017 гг. фактическая продолжительность рабочего времени возросла на всех типах предприятий, однако если на государственных она увеличилась в среднем на 9 часов, то на частных - на 15. Несмотря на установленную КЗоТ продолжительность рабочего времени (168 часов в месяц, или 40 часов в неделю), объем переработки на частных предприятиях к 2017 г. оказался весьма существенным: в среднем 5 часов - на частных предприятиях с участием государства и 11 - на частных предприятиях без участия государства.

Вычисление размера почасовой оплаты (путем деления размера получаемого заработка за 30 дней на фактически отработанное время за 30 дней) показало, что различия в часовом заработке у работников организаций с разными формами собственности не столь значительны по сравнению с величиной отработанного времени. Об этом свидетельствуют сопоставление значений коэффициента Фише$\mathrm{pa}^{14}$, величина которого на несколько порядков выше по затратам времени, чем по часовой оплате (так, в 2017 г. в первом случае $-\mathrm{F}=109,4$, а во втором $-\mathrm{F}=7,6$ ). Таким образом, можно утверждать, что более высокий размер зарплаты у работников

14 F-статистика Фишера, используемая в однофакторном дисперсионном анализе, служит для проверки нулевой гипотезы о равенстве средних. Как правило, при $\mathrm{F} \geq 4,0$ нулевая гипотеза может быть опровергнута. 
частных предприятий обеспечивается преимущественно за счет больших затрат рабочего времени, а не благодаря лучшей организации труда. Этот вывод сохраняется и при введении в модель анализа контрольных переменных: наличия высшего образования и принадлежности к мужчинам моложе 40 лет $^{15}$. Однако удовлетворенность зарплатой вплоть до 2014 г. была значимо выше у работников частных предприятий, сотрудников которых отличает и более высокий уровень уверенности в занятости на рынке труда в случае потери работы. В 2017 г. различия стали более существенными, что, на первый взгляд, можно объяснить более высокими долями молодых (до 30) лет и меньшей - пожилых работников (старше 50 лет), занятых на частных предприятиях по сравнению с государственными. Но и при контроле возрастной принадлежности выявленные различия сохраняются.

Таблица 2. Результирующие показатели трудового поведения в зависимости от занятости на государственных либо частных предприятиях, данные по объединенному массиву РМЭЗ-ВШЭ, 1994-2017 гг.

\begin{tabular}{|c|c|c|c|c|c|c|c|}
\hline \multirow{2}{*}{ Показатели по типам предприятий } & \multicolumn{7}{|c|}{ Годы опроса } \\
\hline & $1994 *$ & 1998 & 2002 & 2006 & 2010 & 2014 & 2017 \\
\hline \multicolumn{8}{|c|}{ Размер заработной платы (руб. в месяц), средние значения } \\
\hline Государственные & 245820 & 805 & 3195 & 7105 & 13025 & 20525 & 22860 \\
\hline Частные & 352155 & 1135 & 4390 & 9350 & 16495 & 24335 & 28310 \\
\hline \multicolumn{8}{|c|}{ Фактическая продолжительность рабочего времени (часов в месяц) } \\
\hline Государственные & 154 & 157 & 157 & 164 & 160 & 165 & 163 \\
\hline Частные & 163 & 163 & 173 & 177 & 176 & 177 & 178 \\
\hline \multicolumn{8}{|c|}{ Часовая оплата труда с учетом отработанного времени (руб. в час), средние значения } \\
\hline Государственные & $1968 n s$ & 6 & 22 & 48 & 90 & 134 & 153 \\
\hline Частные & $2328 \mathrm{~ns}$ & 8 & 28 & 58 & 102 & 147 & 177 \\
\hline \multicolumn{8}{|c|}{ Удовлетворенность зарплатой, средние значения, минимум - 1, максимум - 5} \\
\hline Государственные & $* *$ & $* *$ & 2,12 & 2,42 & 2,50 & $2,94 \mathrm{~ns}$ & 2,83 \\
\hline Частные & $* *$ & $* *$ & 2,54 & 2,66 & 2,78 & $2,96 \mathrm{~ns}$ & 2,99 \\
\hline \multicolumn{8}{|c|}{ Уверенность в занятости на рынке труда, средние значения, минимум -1 , максимум - 5} \\
\hline Государственные & 2,48 & $2,20 \mathrm{~ns}$ & $2,91 \mathrm{~ns}$ & 2,98 & 2,91 & 3,05 & 2,86 \\
\hline Частные & 2,85 & $2,30 \mathrm{~ns}$ & $2,98 \mathrm{~ns}$ & 3,23 & 3,12 & 3,17 & 3,03 \\
\hline \multicolumn{8}{|c|}{ Удовлетворенность работой в целом, средние значения, минимум - 1, максимум - 5} \\
\hline Государственные & $* *$ & $* *$ & $3,49 \mathrm{~ns}$ & $3,71 \mathrm{~ns}$ & 4,05 & 4,27 & 4,23 \\
\hline Частные & $* *$ & $* *$ & $3,44 \mathrm{~ns}$ & $3,64 \mathrm{~ns}$ & 3,94 & 4,11 & 4,14 \\
\hline
\end{tabular}

*1994 г., тыс. руб.

** Нет данных.

ns - различия незначимы, все остальные значимы на уровне $\mathrm{p} \leq 0,001$.

15 Использовался метод двухфакторного дисперсионного анализа (определение эффектов взаимодействия членов на основе построения общей линейной модели). Данный вывод актуален для всех контролируемых годов опроса. 
В целом бытовавший ранее стереотип о большей привлекательности (особенно для молодежи) занятости на частных предприятиях ввиду хорошего заработка постепенно утрачивает свое значение. На них можно заработать больше, чем на государственных, но только за счет больших временных затрат при допущении заведомо худших условий труда и возможностей для нормальной личной и семейной жизни. Так, семейные мужчины на всех типах предприятий зарабатывали существенно больше, чем мужчины, не состоящие в браке, тогда как среди женщин таких различий не выявлено; переработки также оказались значимо выше у мужчин с семейными обязательствами. При этом наибольшие различия в размерах заработка и продолжительности рабочего времени в зависимости от наличия семейных обязанностей обнаружены среди мужчин, занятых на частных предприятиях без участия государства: в среднем (по данным 2017 г.) мужчины, состоящие в браке, зарабатывают на 6 тыс. руб. больше и работают на 3 часа в неделю дольше, чем их неженатые коллеги; на частных предприятиях чаще заняты представители домохозяйств с наличием детей до 18 лет, чем без детей. Эта тенденция прослеживается по всем годам опроса. Таким образом, можно предположить, что более тяжелое состояние домохозяйства способствует выбору в пользу работы на частных предприятиях.

Нашла определенное подтверждение и гипотеза о том, что на частных предприятиях с большей вероятностью можно встретить работников с высоким трудовым потенциалом. Исследование показало, что на частных предприятиях без участия государства сосредоточена более значимая доля работников с высоким уровнем физиологического и психологического ресурса (молодых, здоровых, уверенных в занятости на рынке труда). Собирательная типологическая категория работников с высоким ресурсным потенциалом была образована на основе вычисления методом конъюнкции. Ее составили респонденты не старше 40 лет, оценивающие свое здоровье как очень хорошее и хорошее, уверенные (скорее и полностью), что они в случае увольнения или закрытия предприятия найдут работу не хуже имеющейся ${ }^{16}$. Доля работников, соответствующая этим трем критериям, последовательно возрастала (с 3\% в 1994 г. до 5\% в 2017 г.). На частных предприятиях в 2017 г. их доля составила 7\% против 3\% на частных с участием государства и $4 \%$ на государственных, а на малых частных предприятиях (с численностью работников до 100 чел.) их доля была еще выше - 8\%. Именно для данного типа работников характерны основные признаки стратегии максимизации труда (более высокий заработок при максимальной продолжительности рабочего времени).

Сохранение более существенных долей высокоресурсных работников на частных предприятий и более тяжелые (в сравнении с предприятиями других форм собственности) условия для хорошего заработка могут рассматриваться как скрытый потенциал роста социальной напряженности труда, теневой занятости и самозанятости.

\footnotetext{
16 Предположение о высокой роли образования в повышении ресурса работника не оправдалось, т.к. и при отсутствии высшего образования демонстрируется высокая уверенность на рынке труда, а работники пожилого возраста (старше 60 лет) чаще имеют высшее образование, чем более молодые.
} 


\section{Фактор стабильной занятости}

Предлагаемый исследователями набор характеристик работников, занятых на условиях прекарной занятости [Тощенко 2018], позволяет вычислить обратную им категорию стабильно занятых работников. К показателям стабильной занятости (с учетом их наличия в базе РМЭЗ) были отнесены официальное оформление занятости, отсутствие долгов по зарплате и случаев ее снижения, продолжительность рабочей недели в диапазоне нормативной (36-40 часов в неделю), отсутствие случаев вынужденной отправки в неоплачиваемый отпуск и профессиональной и трудовой мобильности за последний год.

Изменения в стабильности занятости в динамике 2002-2017 гг. ${ }^{17}$ заметны только по показателям наличия долгов по зарплате и смены мест работы и профессии. К 2017 г. существенно (на 20\%) снизилась доля работников, указавших на задолженность по зарплате, и почти на столько же (18\%) повысилась доля, обозначивших отсутствие признаков трудовой и профессиональной мобильности. В целом, можно утверждать, что для абсолютного большинства российских работников (за исключением ситуации с рабочим временем) характерны признаки стабильной занятости (таблица 3).

Таблица 3. Показатели стабильности занятости наемных работников, данные РМЭЗ-ВШЭ, 2002-2017 гг., \% утвердительных ответов

\begin{tabular}{|l|c|c|c|c|c|}
\hline \multirow{2}{*}{ Показатели } & \multicolumn{5}{|c|}{ Годы опроса } \\
\cline { 2 - 7 } & $\mathbf{2 0 0 2}$ & $\mathbf{2 0 0 6}$ & $\mathbf{2 0 1 0}$ & $\mathbf{2 0 1 4}$ & $\mathbf{2 0 1 7}$ \\
\hline Оформлены официально & 96 & 93 & 92 & 92 & 91 \\
\hline Предприятие не имеет долгов по зарплате & 83 & 94 & 95 & 97 & 97 \\
\hline $\begin{array}{l}\text { В течение последних 12 месяцев не уменьшали зарплату } \\
\text { (принудительно не сокращали часы работы) }\end{array}$ & 92 & 95 & 93 & 95 & 94 \\
\hline $\begin{array}{l}\text { В течение последних 12 месяцев не отправляли в вынужденный } \\
\text { неоплачиваемый отпуск }\end{array}$ & 98 & 98 & 97 & 98 & 98 \\
\hline Не меняли ни место работы, ни профессию & 79 & 78 & 81 & 81 & 85 \\
\hline Работают в пределах 36-40 часов в неделю & 48 & 46 & 50 & 52 & 53 \\
\hline Количество опрошенных & $\mathbf{3 6 8 4}$ & $\mathbf{4 7 1 9}$ & $\mathbf{6 9 0 3}$ & $\mathbf{5 9 2 7}$ & $\mathbf{5 8 6 5}$ \\
\hline
\end{tabular}

Доля работников с официальным оформлением занятости, под которой понимается работа по трудовой книжке, трудовому контракту или соглашению, постепенно снижается (на 6\% по сравнению с 1994 г.). Как и следовало ожидать (по данным 2017 г.), на условиях официально оформленной занятости работало

17 За начальную точку отсчета брались данные за 2000 г. с учетом того, что по некоторым вопросам (уменьшение зарплаты, принудительное сокращение рабочего времени) в массиве РМЭЗ есть данные только с этого года. 
абсолютное большинство занятых в государственных организациях (99\%), и существенно меньше на частных - 85\%. Как правило, это специалисты высшего уровня квалификации (99\%), специалисты среднего уровня квалификации, чиновники и офисные служащие (96\%), реже - работники сферы услуг и торговли (87\%) и неквалифицированные рабочие всех отраслей (84\%).

Позитивная динамика наблюдается в показателях отсутствия долгов по зарплате (с 65\% в 1994 г. до 97\% в 2017 г.) и вынужденных отпусков (с 88\% в 1994 г. до $98 \%$ в 2017 г.). Также абсолютное большинство работников (по имеющимся данным, начиная с 2000 г.) указывает на отсутствие случаев уменьшения зарплаты и принудительного сокращения часов работы.

Среди других показателей стабильности в занятости в отдельном анализе нуждаются проявления внешней (межфирменной) трудовой и профессиональной мобильности ${ }^{18}$. Исходя из наблюдаемой динамики изменений, можно заявлять о вынужденном характере мобильности, подогреваемой кризисными явлениями (например, первые годы после дефолта). Так, замеченные в 1999 и 2000 гг. проявления резкой смены места работы и профессии (в эти годы она доходила почти до 20\%) уступили место заметному снижению (почти в 2 раза) этого показателя. В 2017 г. доля сменивших и место работы, и профессию составила 7\%. Замечено, что чаще других переходили на другое место работы и приобретали другую профессию неквалифицированные рабочие, а крайне редко - специалисты высшего уровня квалификации: так, в 2017 г. первых насчитывалось в 3 раза больше, чем вторых (12 и 4\% соответственно). Этот факт также может рассматриваться как показатель вынужденной мобильности. Молодые работники (до 30 лет) в два раза чаще меняли место работы и профессию, чем представители средневозрастной группы (30-39 лет) (18 и 9\% соответственно) и примерно в три раза чаще, чем в старших возрастных группах.

С повышением трудовой и профессиональной мобильности важнейшие показатели результатов трудового поведения ухудшаются. Выявлено, что вне зависимости от формы собственности предприятия, профессионального статуса и возраста работников размер заработной платы и удовлетворенность работой выше у тех, кто не менял ни место работы, ни профессию, что еще раз подчеркивает вынужденный характер мобильности российских работников. Единственный показатель трудового поведения, с которым тесно связаны проявления мобильности, - это уверенность на рынке труда; более того, можно утверждать, что она является органическим продолжением мобильности. Во все годы опроса более высокий уровень уверенности на рынке труда демонстрировали те работники, которые сменили место работы, но не сменили профессию, либо сменили и место работы, и профессию. Полученный на практике опыт смены работы или профессии способствует уверенности, что в случае необходимости они смогут найти работу не хуже той, на которой работают сейчас.

Фактические затраты рабочего времени могут рассматриваться не только как показатель результата трудового поведения домохозяйств, но и сами выступать в качестве структурирующей основы для понимания их роли в отношении зара-

\footnotetext{
18 Формулировка вопроса - «Пожалуйста, вспомните и скажите, Вы сменили место работы или профессию по сравнению с ноябрем предыдущего года или все осталось по-прежнему?». Подсказки: (1) профессия и место работы остались прежними; (2) сменили профессию, но не сменили место работы; (3) сменили место работы, но не сменили профессию; (4) сменили и место работы, и профессию.
} 
ботка, показателей удовлетворенности и сбалансированности работы и семьи. Что касается диапазона нормативной величины рабочего времени (36-40 часов в неделю), то можно выделить отклоняющиеся группировки затрат времени переработок (более 40 часов) и неполного рабочего времени (менее 36 часов в неделю). Обозначенные категории тесно связаны с отраслью занятости, профессиональным статусом работников, а также с формой собственности предприятий. В среднем по объединенному массиву работают с неполной продолжительностью рабочей недели $11 \%$ россиян, с переработками (41-84 часа) - 37\%. Неполной величиной рабочего времени чаще всего охвачены не только наиболее уязвимые категории работников (неквалифицированные рабочие - 27\%), но и специалисты высшего уровня квалификации (23\%), намного реже, чем в среднем, - квалифицированные рабочие (4\%). Напротив, перерабатывают чаще других работники сферы торговли и услуг (64\% респондентов), а также квалифицированные рабочие, использующие машины и механизмы (50\%). В сфере науки, образования, здравоохранения и социального обслуживания чаще работают неполную рабочую неделю (27\%), в бытовом обслуживании и торговле, а также строительстве, транспорте и связи чаще перерабатывают (48 и 47\% соответственно); на государственных предприятиях чаще не дорабатывают (18\%), а на частных перерабатывают (43\%). Учет социально-демографических характеристик показывает, что мужчины чаще перерабатывают, а женщины чаще работают менее 36 часов в неделю. С возрастом величина переработок уменьшается и увеличивается доля занятых неполную рабочую неделю (к последним чаще всего относятся работники старше 60 лет - каждый пятый). Семейные мужчины чаще перерабатывают, чем не состоящие в браке (45 и 39\% соответственно), при этом наличие детей в браке не снижает, а, напротив, увеличивает долю нагрузок в рабочем времени (42 против 34\% среди состоящих в браке без детей). Характерно, что замужние женщины, имеющие одного ребенка до 18 лет, не отличаются по неполной занятости от незамужних женщин, и различия в пользу большей доли включенности вторых в неполную занятость становятся значимыми при наличии двух и более детей до 18 лет.

Принадлежность работников к группам, различающимся по продолжительности рабочего времени, является весьма значимым фактором различий в показателях результативности в трудовом поведении, за исключением удовлетворенности заработком (таблица 4).

Предполагалось, что большая продолжительность рабочего времени должна быть связана с более высоким размером заработка, однако явные различия наблюдаются преимущественно в отношении занятых неполную рабочую неделю. По результатам множественного сравнения не обнаружено значимых различий между перерабатывающими и работающими в пределах нормы в 2010 и 2014 гг. ${ }^{19}$. Отсутствие данных различий сохраняется и при учете в качестве контрольного фактора - наличия высшего образования.

Часовая оплата, как и следовало ожидать, всегда (за исключением 2002 г.) была выше среди работающих неполную рабочую неделю. То, что денежное вознаграждение за час труда выше при меньшей временной загрузке, может рассматриваться как одно из оптимальных оснований при выборе стратегий неполной занятости (особенно для женщин, состоящих в браке и имеющих несовершеннолетних детей). 
Таблица 4. Результирующие показатели трудового поведения в зависимости от принадлежности к группам по продолжительности рабочего времени, данные РМЭЗ-ВШЭ, 2002-2017 гг.

\begin{tabular}{|c|c|c|c|c|c|}
\hline \multirow{2}{*}{$\begin{array}{l}\text { Группы по продолжительности рабочего времени } \\
\text { (часов в неделю) }\end{array}$} & \multicolumn{5}{|c|}{ Годы опроса } \\
\hline & 2002 & 2006 & 2010 & 2014 & 2017 \\
\hline \multicolumn{6}{|c|}{ Размер заработной платы (руб. в месяц), средние значения } \\
\hline до 35 часов & 2520 & 6415 & 11480 & 11480 & 19170 \\
\hline $36-40$ & 3815 & 8300 & 15475 & 23575 & 26815 \\
\hline $41-84$ & 4290 & 9010 & 15600 & 23660 & 28460 \\
\hline \multicolumn{6}{|c|}{ Часовая оплата труда с учетом отработанного времени (руб. в час), средние значения } \\
\hline до 35 часов & $27 \mathrm{~ns}$ & 73 & 130 & 183 & 224 \\
\hline $36-40$ & $25 \mathrm{~ns}$ & 55 & 102 & 150 & 171 \\
\hline $41-84$ & $25 \mathrm{~ns}$ & 48 & 82 & 121 & 152 \\
\hline \multicolumn{6}{|c|}{ Уверенность в занятости на рынке труда, средние значения, минимум -1 , максимум - 5} \\
\hline до 35 часов & 3,11 & 3,21 & 3,21 & 3,18 & $3,04 \mathrm{~ns}$ \\
\hline $36-40$ & 2,75 & 2,98 & 2,95 & 3,04 & $2,91 \mathrm{~ns}$ \\
\hline $41-84$ & 3,08 & 3,21 & 3,10 & 3,20 & $3,03 \mathrm{~ns}$ \\
\hline \multicolumn{6}{|c|}{ Удовлетворенность работой в целом, средние значения, минимум - 1, максимум - 5} \\
\hline до 35 часов & 3,31 & 3,44 & 3,58 & 3,73 & 3,81 \\
\hline $36-40$ & 3,42 & 3,48 & 3,66 & 3,75 & 3,71 \\
\hline $41-84$ & 3,26 & 3,33 & 3,53 & 3.65 & 3,63 \\
\hline
\end{tabular}

ns - различия незначимы, все остальные значимы на уровне $\mathrm{p} \leq 0,001$.

Обнаруженный факт (за исключением 2017 г.) более высокой уверенности в занятости при отклонении в меньшую либо большую сторону от нормальной продолжительности рабочей недели может рассматриваться как один из показателей рыночной модели поведения. Можно утверждать, что росту уверенности в занятости в большей мере способствуют не признаки ее стабильности, а, напротив, различные проявления непостоянства и изменчивости. Дополнительным подтверждением этому является установленная значимая связь между переработками и большей частотой трудовой и профессиональной мобильности.

Удовлетворенность работой в целом выше у работников с нормативной рабочей неделей (за исключением 2017 г.), однако при множественном сравнении значимые различия обнаружены только между нормой рабочего времени и переработками. 


\section{Работа и семья}

В соответствии с теорией максимизации труда предполагалось, что работники, ориентированные на больший размер заработка посредством более продолжительного рабочего времени, в меньшей степени хотели бы отдавать свое время семейным и домашним делам. Однако анализ показал обратное: по мере увеличения заработка и рабочего времени растет ориентация на то, чтобы больше времени уделять семье, и по большей части это связано с продолжительностью рабочей недели. При ее максимумах (51-84 часов) почти 50\% работников хотели бы уделять больше времени семье, тогда как в среднем по выборке это цифра составляет $36 \%$. При размере заработка, равного двум медианам, доля работников с ориентацией на семью увеличивается до 40\%. Вместе с тем с учетом формы собственности и половозрастных характеристик работников данная гипотеза может быть применима только в отношении фактора затрат времени и не применима к фактору заработка. Работники частных предприятий, мужчины моложе 40 лет, не готовы поступиться возможностью заработка ради семьи. Наиболее сильная связь (коэффициент Крамера - 0,466) зафиксирована между удовлетворенностью временем, которое затрачивается на занятия семейными и домашними делами, и желанием его увеличить. Если это время (по оценкам) слишком мало, то 93\% среди тех работников, которых величина времени на занятия семейными и домашними делами не устраивает, против 28\% тех, кого это время устраивает, хотели бы его увеличить.

Таблица 5. Различия в оценках перспектив улучшения положения семьи у работников разного типа предприятий, групп по продолжительности рабочей недели и проявлений мобильности, средние значения, данные РМЭЗ-ВШЭ, 2002-2017 гг.

\begin{tabular}{|l|c|c|c|c|c|c|}
\hline \multirow{2}{*}{ Факторы } & \multicolumn{5}{|c|}{ Годы опроса } \\
\cline { 2 - 7 } \multicolumn{2}{|l|}{} & $\mathbf{2 0 0 2}$ & $\mathbf{2 0 0 6}$ & $\mathbf{2 0 1 0}$ & $\mathbf{2 0 1 4}$ & $\mathbf{2 0 1 7}$ \\
\hline Форма собственности предприятия & 3,14 & 3,26 & 3,12 & 3,04 & 3,13 \\
\hline Государственные & 3,30 & 3,42 & 3,32 & 3,14 & 3,19 \\
\hline Частные & \multicolumn{5}{|l|}{} \\
\hline Группы по продолжительности рабочего времени & 3,27 & 3,31 & 3,23 & 3,11 & 3,19 \\
\hline до 35 часов & 3,16 & 3,31 & 3,37 & 3,07 & 3,13 \\
\hline $36-40$ & 3,31 & 3,41 & 3,31 & 3,14 & 3,22 \\
\hline $41-84$ & & & & \\
\hline Трудовая и профессиональная мобильность & 3,15 & 3,28 & 3,19 & 3,02 & 3,11 \\
\hline Профессия и место работы остались прежними & 3,18 & 3,42 & 3,32 & 3,12 & 3,16 \\
\hline Сменили профессию, но не сменили место работы & 3,46 & 3,48 & 3,47 & 3,40 & 3,33 \\
\hline Сменили место работы, но не сменили профессию & 3,52 & 3,53 & 3,57 & 4,46 & 3,55 \\
\hline Сменили и место работы, и профессию & & & \\
\hline
\end{tabular}

1 - минимум, 5 - максимум

Все различия значимы на уровне $\mathrm{p} \leq 0,001$. 
И поскольку абсолютное большинство работников (79\%) оно устраивает, то и желание поступаться работой (особенно размером заработка) ради семьи низкое. Только примерно каждый десятый из числа опрошенных готов сократить личный доход ради семьи. Рассмотрим различия в оценках перспектив улучшения положения семьи ${ }^{20}$ в зависимости от контролируемых факторов (таблища 5).

Как выяснилось, перспективы улучшения положения семьи связываются со следованием модели максимизации труда (занятостью на частных предприятиях, где можно еще больше заработать благодаря продолжительному и интенсивному труду), с более высокой продолжительностью рабочего времени (за исключением 2010 г.) и с трудовой и профессиональной мобильностью. Кроме того, оптимизм в отношении перспектив семьи во многом обусловлен принадлежностью к высокоресурсным группам работникам (прежде всего молодым мужчинам до 40 лет), в меньшей степени - наличием высшего образования и определенной отраслью занятости.

\section{Итоговые результаты}

Несомненно, что для домохозяйств ведущим результатом трудового поведения вне зависимости от величины временных затрат и личностных ресурсов работника (здоровье, возраст, образование) является размер заработка. В целях выявления вклада основных переменных в объяснение дисперсии размеров заработка был проведен множественный линейный пошаговый регрессионный анализ с использованием фиктивных переменных. Для этого был создан ряд дихотомических переменных, по которым референтные значения предписывались тем группам респондентов, у которых размер зарплаты оказался выше по сравнению с остальными $^{21}$. Результаты анализа показали, что вклад основной контролируемой переменной (занятость на частных предприятиях) уступает влиянию наличия высшего образования и принадлежности работников к мужскому полу (таблица б).

Представляется актуальным обратить внимание на последовательное приращение по годам (до 2017 г.) значений коэффициентов, связанных с наличием высшего образования. В 2017 г. на фоне снижения роли высшего образования в объяснении дисперсии размеров заработка несколько увеличилось влияние половой принадлежности и занятости на частных предприятиях. Незначительным по сравнению с тремя указанными предикторами выглядит влияние более продолжительной по времени занятости, молодого возраста и состояния в браке. В целом по совокупному значению коэффициента детерминации можно утверждать лишь о незначительной величине объясняющей силы введенных в анализ предикторов размера заработка работников.

\footnotetext{
20 Формулировка вопроса - «Как Вы думаете, через 12 месяцев Вы и Ваша семья будете жить лучше или хуже, чем сегодня?». 1 - намного хуже, 5- намного лучше (после перекодировки).

21 Так, учитывая, что у мужчин средний размер зарплаты существенно выше, чем у женщин, код 1 присваивался мужчинам, 0 - женщинам. По этому же принципу: 1 - занятым на частных предприятиях, 0 - государственных; 1 - при наличии высшего образования, 0 - при его отсутствии; 1 - при продолжительности рабочей недели более 40 часов, 0 - менее 40 часов; 1 - моложе 40 лет, 1 - старше 40 лет; 1 - состоящим в браке, 0 - не состоящим в браке. Различия групп работников по мобильности и здоровью не были включены в анализ, т.к. они не образовали модели ни по одному из годов опроса.
} 
Таблица 6. Предикторы размера получаемой зарплаты, стандартизированные коэффициенты Бетта

\begin{tabular}{|l|c|c|c|c|c|}
\hline \multirow{2}{*}{ Модели } & \multicolumn{5}{|c|}{ Годы опроса } \\
\cline { 2 - 7 } & $\mathbf{2 0 0 2}$ & $\mathbf{2 0 0 6}$ & $\mathbf{2 0 1 0}$ & $\mathbf{2 0 1 4}$ & $\mathbf{2 0 1 7}$ \\
\hline Принадлежность к мужскому полу & 0,202 & 0,197 & 0,222 & 0,224 & 0,240 \\
\hline Занятость на частных предприятиях & 0,154 & 0,142 & 0,135 & 0,101 & 0,114 \\
\hline Наличие высшего образования & 0,215 & 0,246 & 0,273 & 0,286 & 0,282 \\
\hline Работают более 40 часов в неделю & 0,053 & $\mathrm{~ns}$ & $\mathrm{~ns}$ & $\mathrm{~ns}$ & 0,047 \\
\hline Моложе 40 лет & $\mathrm{ns}$ & 0,075 & 0,051 & $\mathrm{~ns}$ & $\mathrm{~ns}$ \\
\hline Состоят в браке & $\mathrm{ns}$ & 0,050 & 0,033 & 0,038 & 0,035 \\
\hline Совокупный R-квадрат, \% & 11,2 & 11,9 & 13,7 & 12,9 & 14,5 \\
\hline
\end{tabular}

ns - отсутствие статистически значимых значений коэффициентов. Все остальные значимы на уровне $\mathrm{p} \leq 0,001$.

Подводя итоги, можно утверждать, что включение в анализ занятости работников на отличающихся по форме собственности предприятиях как потенциального фактора различий в показателях результатов трудового поведения получило доказательное оправдание. В настоящее время на частных предприятиях сосредоточена более высокая по сравнению с государственными доля работников с высоким уровнем физиологического и психологического ресурсов (молодых, здоровых, уверенных в занятости на рынке труда). Установлено, что более высокий размер зарплаты работников частных предприятий обеспечивается преимущественно за счет больших затрат рабочего времени; переработки негативно сказываются на уровнях удовлетворенности работой. Более высокий уровень стремления работников уделять время семье при максимальных переработках не находит своего воплощения из-за неготовности ради семьи поступиться возможностями заработка. Все это является свидетельством незавершенной адаптации, вынужденной необходимости больше работать ради обеспечения приемлемого материального благополучия семьи. Вместе с тем стратегия максимизации труда, распространившаяся в конце 1990-х гг. среди активных молодых работников, сегодня теряет свой потенциал. К 2017 г. рост учитываемых показателей результатов трудового поведения с учетом контрольных факторов приостановился либо снизился, также как и уменьшились дифференцирующее влияние формы собственности предприятия и переработок рабочего времени. Выявленный в ходе анализа рост уверенности в занятости при различных проявлениях динамичности в поведении (трудовой и профессиональной мобильности), отклонений в меньшую либо большую сторону от нормальной продолжительности рабочей недели может рассматриваться не только как показатель рыночной модели поведения, но и как потенциальный фактор ухода работников из формального рынка труда в сферу самозанятости, неформальной экономики в целом. 


\section{Литература}

Андреев В.К. (2007) О праве частной собственности в России (критический очерк). М.: Волтерс Клувер.

Андреева Ю.В., Лукьянова Е.Л. (2019) Между работой, детьми и торговым центром: баланс жизни и труда в семьях молодых российских рабочих // Мониторинг общественного мнения: Экономические и социальные перемены. № 3. С. 122-141.

Бауман 3. (2005) Индивидуализированное общество. М.: Логос.

Бек У. (2000) Общество риска: на пути к другому модерну. М.: Прогресс Традиция.

Беляева Л.А. (2017) Отношения собственности в современной России: социальные эффекты и перспективы // Общественные науки и современность. № 6. С. 31-42.

Бобков В.Н., Вередюк О.В., Колосова Р.П., Разумова Т.О. (2014) Занятость и социальная прекаризация в России: введение в анализ. М.: ТЕИС.

Бочаров В.Ю. (2019) Модели трудового поведения рабочей молодежи Урала // Петербургская социология сегодня. № 12. С. 22-46.

Верховин В.И. (2003) Трудовое поведение. М.: РУДН.

Гимпельсон В.Е., Капелюшников Р.И. (ред.) (2017) Мобильность и стабильность на российском рынке труда. М.: ВШЭ.

Гимпельсон В.Е., Капелюшников Р.И., Шарунина А.В. (2016) «Дороги, которые мы выбираем»: перемещения на внешнем и внутреннем рынках труда // Экономический журнал ВШЭ. Т. 20. № 2. С. 201-242.

Гимпельсон В.Е., Шарунина А.В. (2015) Потоки на российском рынке труда: 2000-2012 гг. // Экономический журнал ВШЭ. Т. 19. № 3. С. 313-348.

Голенкова 3.Т., Голиусова Ю.В. (2015) Прекариат как новая группа наемных работников // Уровень жизни населения регионов России. № 1. С. 47-57.

Горшков М.К., Пэйлинь Ли, Голенкова 3.Т. (ред.) (2013) Россия и Китай. Изменения в социальной структуре общества. М.: Новый хронограф.

Лимаренко А.П., Прилепко Е.М. (2014) Семья и работа: поиск баланса семейных и профессиональных ролей // Социология. № 4. С. 100-111.

Мкртчян Г.М., Чистяков И.М. (2000) Молодежь Москвы на рынке труда // Социологические исследования. № 12. С. 42-49.

Нуреев Р.М. (ред.) (2001) Экономические субъекты постсоветской России (институциональный анализ). М.: МОНФ.

Патрушев В.Д., Темницкий А.Л. (1994) Собственность и отношение к труду // Социологические исследования. № 4. С. 52-59.

Полякова Н.В. (1998) Экономическое поведение. Иркутск: ИГЭА.

Праведников А.В. (2018) Влияние напряженности труда и темпоральных характеристик занятости на баланс семьи и работы // Вестник ПНИПУ. Социально-экономические науки. № 3. С. 174-183.

Радаев В.В. (2005) Экономическая социология. М.: ВШЭ.

Рождественская Е.Ю. (2011) Концепция баланса жизни и труда: уроки европейской социальной политики и российские перспективы // Журнал исследований социальной политики. Т. 9. № 4. С. 439-454.

Стэндинг Г. (2014) Прекариат: новый опасный класс. М.: Ад Маргинем Пресс.

Темницкий А.Л. (2007) Теоретико-методологические подходы к исследованию трудового поведения // Социологические исследования. № 6. С. 60-71.

Темницкий А.Л. (2014) Становление наемного работника рыночного типа в условиях трансформации отношений собственности // Социологические исследования. № 5. C. $47-55$.

Темницкий А.Л. (2019) Роль сбалансированности работы и семьи в достижении жизненного успеха у наемных работников России // Мониторинг общественного мнения: Экономические и социальные перемены. № 3. С. 281-298.

Тощенко Ж.Т. (2015) Прекариат - новый социальный класс // Социологические исследования. № 6. С. 3-13. 
Тощенко Ж.Т. (2018) Прекариат: от протокласса к новому классу. М.: Наука.

Шкаратан О.И., Карачаровский В.В., Гасюкова Е.Н. (2015) Прекариат: теория и эмпирический анализ (на материалах опросов в России, 1994-2013) // Социологические исследования. № 12. С. 99-110.

Ядов В.А. (ред.) (2006) Социология труда. Теоретико-прикладной словарь. СПб.: Наука.

Bowen D.E., Ostroff C. (2004) Understanding HRM - Firm Performance Linkages: the Role of the "Strength" of the HRM System // Academy of Management Review, vol. 29, no 2, pp. 200-221.

\title{
The Labor Productivity of Household Members in the Context of Transforming Property Relations and Employment Conditions
}

\section{A. TEMNITSKIY*}

\begin{abstract}
*Alexander Temnitskiy - PhD in Sociology, Associate Professor, Sociological Department, Moscow State Institute of International Relations (MGIMO); Senior Researcher, Institute of Sociology of the FCTAS RAS. Address: 76, Vernadskogo Av., Moscow, 119454, Russian Federation.E-mail: taleksandr@list.ru

Citation: Temnitskiy A. (2020) The Labor Productivity of Household Members in the Context of Transforming Property Relations and Employment Conditions. Mir Rossii, vol. 29, no 2, pp. 134-155 (in Russian). DOI: 10.17323/1811-038X-2020-29-2-134-155
\end{abstract}

\begin{abstract}
This article considers labor productivity from the perspective of household goals and interests. In particular, it looks at hourly wages, satisfaction with pay and work in general, employment certainty, and the prospects of improving family well-being. The empirical analysis is based on data of the Russia Longitudinal Monitoring Survey Higher School of Economics (RLMS-HSE) for 1994-2017. In the theoretical part of the article, I explain how and why (1) the analysis of modern households can be brought down to the individual level, (2) work behavior can be studied through the lens of its resulting indicators, and (3) the forms of ownership and working conditions in enterprises matter for work behavior and its reflected in the measurement indicators of this behavior.

The study reveals that the formerly prevailing stereotype, according to which being employed in a private enterprise was attractive for its promise of good earnings, is losing its significance. While private enterprises do, in general, offer higher wages compared to state-owned enterprises. Such wages also come with larger time costs, worse working conditions and smaller opportunities for a normal personal and family life. Employees in private enterprises, unlike their counterparts in state enterprises, are more satisfied with their wages. They also express more confidence about their employment and optimism regarding the possibility of improving the well-being of their families. Stable
\end{abstract}


employment conditions (with the exception of those related to the working time) are characteristic of the vast majority of employees in Russian organizations. Labor and professional mobility is predominantly forced, and when it occurs it is also associated with negative changes in work behavior. Finally, the study reveals a paradox: while the respondents do exhibit stronger desires to devote more time to their family along with the growth in their earnings and working time, this desire does not materialize due to the compelling necessity to pursue a labor-maximizing strategy (i.e. work harder to ensure the financial well-being of the family). I argue that workers cannot break this vicious circle on their own, and it requires adjustments in the current state social policies.

Key words: labor behavior, household, labor maximization strategy, work-family balance, property relations, stable employment, labor market, employees

\section{References}

Andreev V.K. (2007) O prave khastnoj sobstvennosti v Rossii (kriticheskij ocherk) [On the Right to Private Property in Russia (Critical Essay)], Moscow: Volters Kluver.

Andreeva Yu.V., Luk'yanova E.L. (2019) Mezhdu rabotoj, det'mi i torgovym tsentrom: balans zhiznii truda v sem'yakh molodykh rossijskikh rabochikh [Between Work, Children and the Shopping Center: the Balance of Life and Work in the Families of Young Russian Workers]. Monitoring obshchestvennogo mneniya: Ekonomicheskie i sotsial'nye peremeny, no 3, pp. 122-141.

Bauman Z. (2005) Individualizirovannoe obshchestvo [The Individualized Society], Moscow: Logos.

Beck U. (2000) Obshchestvo riska: na puti $k$ drugomu modernu [Risk Society: Towards a New Modernity], Moscow: Progress Traditsiya.

Belyaeva L.A. (2017) Otnosheniya sobstvennosti v sovremennoj Rossii: sotsial'nye effekty i perspektivy [Property Relations in Modern Russia: Social Effects and Prospects]. Obshhestvennye nauki i sovremennost', no 6, pp. 31-42.

Bobkov V.N., Veredyuk O.V., Kolosova R.P., Razumova (2014) Zanyatost' $i$ sotsial'naya prekarizatsiya v Rossii: vvedenie v analiz [Employment and Social Precarization in Russia: an Introductory Analysis], Moscow: TEIS.

Bocharov V.Yu. (2019) Modeli trudovogo povedeniya rabochej molodezhi Urala [Models of Labor Behavior of Working Youth in the Urals]. Peterburgskaya sotsiologiya segodnya, no 12 , pp. 22-46.

Bowen D.E., Ostroff C. (2004) Understanding HRM - Firm Performance Linkages: the Role of the "Strength" of the HRM System. Academy of Management Review, vol. 29, no 2, pp. 200-221.

Gimpel'son V.E., Kapelyushnikov R.I. (eds.) (2017) Mobil'nost'i stabil'nost'na rossijskom rynke truda [Mobility and Stability in the Russian Labor Market], Moscow: HSE.

Gimpel'son V.E., Kapelyushnikov R.I., Sharunina A.V. (2016) «Dorogi, kotorye my vybiraem»: peremeshcheniya na vneshnem i vnutrennem rynkakh truda ["The Roads We Choose": Movements in the External and Internal Labor Markets]. The HSE Economic Journal, vol. 20, no 2, pp. 201-242.

Gimpel'son V.E., Sharunina A.V. (2015) Potoki na rossijskom rynke truda: 2000-2012 gg. [Flows in the Russian Labor Market: 2000-2012]. The HSE Economic Journal, vol. 19, no 3, pp. 313-348.

Golenkova Z.T., GoliusovaYu.V. (2015) Prekariat kak novaya gruppa nayomny’xrabotnikov [The Precariat as a New Group of Employees]. Uroven'zhizninaseleniya regionov Rossii, no 1, pp. 47-57. 
Gorshkov M.K., Pehjlin' Li, Golenkova Z.T. (eds.) (2013) Rossiya i Kitaj. Izmeneniya $v$ sotsial'noj strukture obshchestva [Russia and China. Changes in the Social Structure of Society], Moscow: Novyj Khronograf.

Limarenko A.P., Prilepko E.M. (2014) Sem'ya i rabota: poisk balansa semejnykh i professional'nykh rolej [Family and Work: Finding a Balance Between Family and Professional Roles]. Sociology, no 4, pp. 100-111.

Mkrtchyan G.M., Chistyakov I.M. (2000) Molodezh' Moskvy na rynke truda [Moscow Youth in the Labor Market]. Sotsiologicheskie issledovaniya, no 12, pp. 42-49.

Nureev R.M. (ed.) (2001) Ekonomicheskie sub'ekty postsovetskoj Rossii (institutsional'nyj analiz) [Economic Entities of post-Soviet Russia (Institutional Analysis)], Moscow: MONF.

Patrushev V.D., Temnitskiy A.L. (1994) Sobstvennost' i otnoshenie k trudu [Property and Attitude to Work]. Sotsiologicheskie issledovaniya, no 4, pp. 52-59.

Polyakova N.V. (1998) Ekonomicheskoe povedenie [Economic Behavior], Irkutsk: IGEA.

Pravednikov A.V. (2018) Vliyanie napryazhennosti truda i temporal'nykh kharakteristik zanyatosti na balans sem'i i raboty [Influence of Labor Intensity and Temporal Parameters of Employment on Work-family Balance]. Vestnik PNIPU. Sotsial'no-ekonomicheskie nauki, no 3, pp. 174-183.

Radaev V.V. (2005) Ekonomicheskaya sotsiologiya [Economic Sociology], Moscow: HSE.

Rozhdestvenskaya E.Yu. (2011) Kontseptsiya balansa zhizni i truda: uroki evropejskoj sotsial'noj politiki i rossijskie perspektivy [The Concept of the Balance of Life and Work: Lessons of European Social Policy and Russian Prospects]. Zhurnal issledovanij sotsial'noj politiki, vol. 9, no 4, pp.439-454.

Shkaratan O.I., Karacharovskij V.V., Gasyukova E.N. (2015) Prekariat: teoriya i empiricheskij analiz (na materialakh oprosov v Rossii, 1994-2013) [The Precariat: Theory and Empirical Analysis (Based on Surveys in Russia, 1994-2013)]. Sotsiologicheskie issledovaniya, no 12 , pp. $99-110$.

Standing G. (2014) Prekariat: novyj opasnyj klass [The Precariat: a New Dangerous Class], Moscow: Ad Marginem Press.

Temnitskiy A.L. (2007) Teoretiko-metodologicheskie podkhody $\mathrm{k}$ issledovaniyu trudovogo povedeniya [Theoretical and Methodological Approaches to the Study of Labor Behavior]. Sotsiologicheskie issledovaniya, no 6, pp. 60-71.

Temnitskiy A.L. (2014) Stanovlenie naemnogo rabotnika rynochnogo tipa $\mathrm{v}$ usloviyakh transformatsii otnoshenij sobstvennosti [Formation of a Market Employee in the Conditions of Transformation of Property Relations]. Sotsiologicheskie issledovaniya, no 5, pp. 47-55.

Temnitskiy A.L. (2019) Rol' sbalansirovannosti raboty i sem'i v dostizhenii zhiznennogo uspekha u naemnykh rabotnikov Rossii [The Role of Work and Family Balance in Achieving Success in Life for Russian Employees]. Monitoring obshchestvennogo mneniya: Ekonomicheskie i sotsial'nye peremeny, no 3, pp. 281-298.

Toshchenko Zh.T. (2015) Prekariat - novyj sotsial'nyj klass [Precariat - a New Social Class]. Sotsiologicheskie issledovaniya, no 6, pp. 3-13.

Toshchenko Zh.T. (2018) Prekariat: ot protoklassa k novomu klassu [Precariat: from Protoclass to New Cass], Moscow: Nauka.

Verkhovin V.I. (2003) Trudovoe povedenie [Labor Behavior], Moscow: RUDN.

Yadov V.A. (ed.) (2006) Sotsologiya truda. Teoretiko-prikladnoj slovar' [Sociology of Labor. Applied Dictionary], Saint Petersburg: Nauka. 